\title{
Editorials
}

\section{Underprovision of mental health services for children and young people}

\section{NATIONAL FOCUS AND INVESTMENT}

The recent publication of the NHS digital 2017 survey of children and young people's mental health highlights how critical the issue of provision of mental health services for this group is. ${ }^{1}$ Previous policy including Future in Mind, identified core principles needed to improve services and support children and young people's emotional wellbeing and resilience through early intervention and prevention, improving access, care for the most vulnerable, better accountability and transparency, and workforce development. ${ }^{2}$ There was €1.4 billion allocated over 5 years to implement these las reported by the HM Treasury Budget 2015). This was endorsed a year later by the Five Year Forward View for Mental Health, ${ }^{3}$ which added that improvements were needed in crisis care, 7-day care, and in the development of new integrated services.

To achieve these ambitions local transformation plans (LTPS) were created. ${ }^{2}$ Developed by clinical commissioning groups (CCGs), they focus on investing resources for children and young people's mental health across the 'whole' system. The financial investment has been used to train new and existing staff to deliver psychological therapies to children and young people, develop perinatal mental health services, and services for eating disorders. Other outcomes include changing legislation around keeping young people aged $<18$ years in a police cell and the introduction of waiting times for eating disorders and psychosis.

Recently, the green paper public consultation on transforming children and young people's mental health provision ${ }^{4}$ committed to three key proposals which will be piloted; including training a designated senior lead for mental health, funding new mental health support teams (MHSTs), and piloting a 4-week waiting time for access to specialist mental health services. In October 2018, the Government pledged an additional

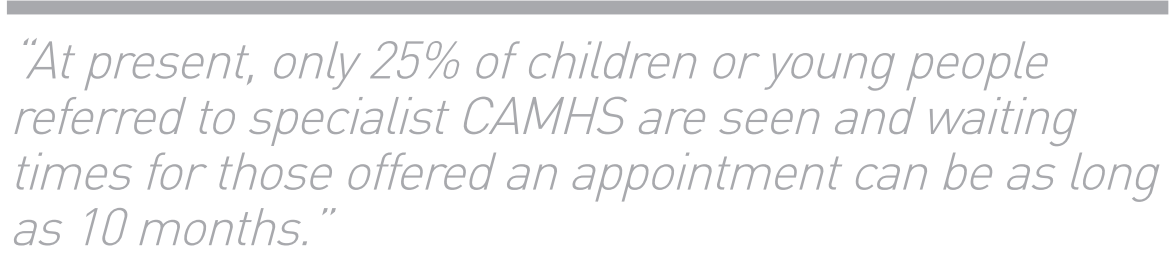

E250 million a year to 2023-2024 for mental health crisis services, which includes those for children and young people.

\section{CHILD AND ADOLESCENT MENTAL HEALTH SERVICES (CAMHS)}

The Future in Mind report identified that significant financial investment is needed due to decades of under-investment and under-resourcing. However, current investment has been based on 2004 data that identified 1 in 10 children suffer from a diagnosable mental illness. ${ }^{5}$ New data shows this has increased to 1 in 8 children. At present, only $25 \%$ of children or young people referred to specialist CAMHS are seen and waiting times for those offered an appointment can be as long as 10 months. ${ }^{6}$ The aim is to increase this to $33 \%$ lwhich means an additional 70000 young people will be treated by 2021). ${ }^{\text {? }}$

The child health agenda focuses on prevention: investing in the health and wellbeing of young people benefits us all, but at some unknown point in the future. Support for prevention was a key recommendation of the Five Year Forward View for Mental Health, but the implementation strategy fell short in identifying specific actions or funding to support delivery at local levels. ${ }^{8}$ The green paper proposes investment in school mental health leads and MHSTs, ${ }^{4}$ which is good for the individual child, but not for their families or communities. This risks children and young people's mental health services becoming separate from the wider child health and wellbeing system, especially in prevention and "universal care. ${ }^{9}$ Investment linked to the green paper recommendations may miss a wide range of other health and social care providers including midwives, GPs, school nurses, and health visitors.

Concerns have been raised around the delivery of the LTPs and transparency of spending. Only a third to a half of CCGs in a YoungMinds survey could demonstrate increased CAMHS investment. Worryingly, many CCGs did not respond, and the risk is that they cannot track their money specific to CAMHS spend or that new money is being used to backfill cuts or to spend on other priorities. ${ }^{10,11}$

Workforce shortages are also a major barrier to transforming children and young people's mental health services. ${ }^{12}$ Staff shortages currently limit the development of more modern preventative children and young people's mental health services (for example, THRIVE) that move away from the 'tiered model' of care.9 At present it is not clear that the necessary workforce exists to deliver this.

\section{MOVING FORWARD}

Children and young people's mental health service improvement is starting from a very low base. ${ }^{13}$ Investment so far has been based on out-of-date information and has not recognised the need to invest to achieve a basic 'standard level' of services, let alone transformational change. Spending so far has been mostly on the health sector, ignoring community and social care, but now there is a new focus on the education system. ${ }^{1}$ Pressure on overall NHS budgets puts individual CCGs in a difficult position. The proposals in the green paper risk placing further pressure on already understaffed services and on the quality and safety of care provided. It is important MHSTs include the general practice team and that open communication between schools and GPs is facilitated to ensure young people in school receive joined-up care. Government must ensure that there is far greater 


\section{“A holistic evidence-informed approach, based \\ on inter-agency partnership, in co-production \\ with children and young people, and with ongoing \\ evaluation is essential if services are to deliver what children and young people want ...}

accountability over where the new money is going and consider ring-fencing current and new funding. Maintaining a prominent focus at a senior strategic level of government and policymakers is critical.

\section{WHAT NEXT?}

There is real opportunity for LTPs to lead the way in improving children and young people's health and wellbeing and achieve transformational change. A holistic evidence-informed approach, based on inter-agency partnership, in co-production with children and young people, and with on-going evaluation is essential if services are to deliver what children and young people want, which is all professionals to work in partnership with them.

This commitment, so far, to children and young people's mental health services is a good start but may fall short of being able to deliver whole system, transformational change. Children and young people's mental health services must remain a top priority if change is to be delivered as a whole system approach through joint working across the NHS, public health, voluntary and community, local authority, education and youth justice sectors. This is the only way to create a system focused on and built around the child/young person and their family. ${ }^{2}$

\section{ADDRESS FOR CORRESPONDENCE}

\section{Elizabeth England}

Royal College of General Practitioners, CIRC Clinical Innovation and Research Centre, 30 Euston Square,

London NW1 2FB, UK

\section{Email: Elizabeth.englandArcgp.org.uk}

\section{Elizabeth England}

RCGP Mental Health Clinical Lead, RCGP, London; Mental Health and Learning Disability Lead, Sandwell and West Birmingham CCG, West Bromwich; GP, Laurie Pike Health Centre, Birmingham and Lillie Road Surgery, London; Non-Executive Director Walsall Manor NHS Healthcare Trust, Walsall.

\section{Faraz Mughal,}

GP and NIHR In-Practice Fellow, Research Institute for Primary Care and Health Sciences, Keele University, Staffordshire.

\section{Funding}

Faraz Mughal is a NIHR In-Practice Fellow. The views expressed in this paper are those of the authors and not necessarily those of the NHS, the NIHR, or the Department of Health and Social Care.

\section{Provenance}

Commissioned; externally peer reviewed.

\section{Competing interests}

Faraz Mughal is RCGP Clinical Fellow in Mental Health, Clinical Innovation and Research Centre. Elizabeth England has declared no competing interests.

DOI: https://doi.org/10.3399/bjgp19X701381

\section{REFERENCES}

1. NHS Digital. Mental health of children and young people in England, 2017 [PAS]. NHS Digital, 2018. https://digital.nhs.uk/data-andinformation/publications/statistical/mentalhealth-of-children-and-young-people-inengland/2017/2017 (accessed 14 Feb 2019).

2. NHS England and the Department of Health. Future in Mind. Promoting, protecting and improving our children and young people's mental health and wellbeing. Crown copyright, 2015.

3. Independent Mental Health Taskforce to the NHS in England. Five Year Forward View for Mental Health. 2016.

4. Department of Health and Department of Education. Transforming Children and Young People's Mental Health Provision: a Green Paper. Presented to Parliament by the Secretary of State for Health and Secretary of State for Education by Command of Her Majesty. Cm 9523. December 2017. https://assets. publishing.service.gov.uk/government/uploads/ system/uploads/attachment_data/file/664855/ Transforming_children_and_young_people_s mental_health_provision.pdf laccessed 14 Feb 2019).

5. Green, H. ᄀMcGinnity, A. Meltzer, H. Mental health of children and young people in Great Britain. HMSO, Palgrave MacMillan. Crown Copyright, 2004

6. The Comptroller and Auditor General. Department of Health \& Social Care, NHS England and Health Education England. Improving children and young people's mental health services. National Audit Office, 2017.

7. Frith, E. CentreForum commission on children and young people's mental health: State of the Nation. CentreForum, 2016.

8. NHS England. Implementing the five year forward view for mental health. NHSE, 2016 https://www.england.nhs.uk/publication/ implementing-the-fyfv-for-mental-health/ laccessed 14 Feb 2019].

9. Wolpert, M, Harris R, Jones M, et al for Anna Freud Centre and The Tavistock and Portman NHS Healthcare Trust. THRIVE the AFC-Tavistock Model for CAMHS. Press CAMHS, 2014. http://www.implementingthrive. org/wp-content/uploads/2016/03/Thrive.pdf (accessed 14 Feb 2019).

10. Earle, J. Children and young people's mental health. BMA, 2016.

11. Young Minds. Children's mental health funding: where is it going? Young Minds, 30 October 2018. https://youngminds.org.uk/blog/childrensmental-health-funding-where-is-it-going/ (accessed 14 Feb 2019).

12. British Medical Association. The state of pre and post-graduate medical recruitment in England. BMA, September 2017.

13. Care Quality Commission. Review of children and young people's mental health services Phase One supporting documentation: Summary of recent policy and literature. Care Quality Commission, 2017. https://www.cqc.org uk/sites/default/files/20171027_cypmhphase1_ literaturereview.pdf (accessed 14 Feb 2019). 